\title{
Systemic retention of ingested cantharidin by frogs*
}

\author{
Thomas Eisner ${ }^{1}$, Jeffrey Conner ${ }^{1 * *}$, James E. Carrel ${ }^{2}$, John P. McCormick ${ }^{2}$, Amy J. Slagle ${ }^{2}$, \\ Carl Gans ${ }^{3}$, James C. O'Reilly ${ }^{3}$ \\ ${ }^{1}$ Section of Neurobiology and Behavior, Cornell University, Seeley G. Mudd Hall, Ithaca, New York 14853, USA \\ ${ }^{2}$ Division of Biological Sciences, Tucker Hall, University of Missouri, Columbia, Missouri 65211, USA \\ ${ }^{3}$ Division of Biological Sciences, University of Michigan, Ann Arbor, Michigan 48109, USA
}

Received May 26, 1990 / Accepted June 28, 1990

\section{Summary}

Frogs (Rana pipiens) fed on blister beetles (Meloidae) or cantharidin, retain cantharidin systemically. After cessation of feeding, they void the compound relatively quickly. Systemic cantharidin does not protect frogs against ectoparasitic feeding by leeches (Hirudo medicinalis) or predation by snakes (Nerodia sipedon). As suggested by our data, and from reports in the early literature, ingestion of cantharidin-containing frogs can pose a health threat to humans.

\section{Key words}

toxin sequestration, predation, human dietary hazard, cantharidin, Coleoptera, Meloidae, Epicauta vittata, Rana, Hirudo, Nerodia
Cantharidin is one of the oldest-known toxins from insects. Produced by blister beetles (family Meloidae), the compound serves these animals effectively in defense against ants and carabid beetles (Carrel \& Eisner 1974). Some meloid enemies, however, are undeterred by cantharidin. Among these are frogs, which apparently consume meloids with impunity (Korschgen \& Moyle 1955; Kelling et al. 1990). A question that arises is whether frogs that ingest meloids retain the cantharidin they acquire with their prey, and whether they are rendered poisonous as a result. Acquired cantharidin could convey a protective advantage on frogs vis à vis any number of natural enemies, and it could also make frogs poisonous to humans. The latter possibility appears to have some basis in fact. On two separate occasions, reported in the early medical literature (Vézien 1861; Meynier 1893), humans have been noted to develop symptoms suggestive of cantharidin poisoning following ingestion of frogs. Both cases involved French soldiers in North Africa who had eaten frogs from field sites infested with meloids and who developed "érections douloureuses et prolongués", a condition known to physicians of the time to be elicited by cantharidin ingestion. Upon dissection, frogs from one of the sites were found to have stomachs replete with meloids (Vézien 1861).

We here report data indicating that frogs do indeed retain cantharidin systemically for some time following ingestion of the poison. We fed both crystalline cantharidin and meloid beetles to frogs, and at intervals after feeding analyzed the frogs' excrescences and body parts for cantharidin content. In addition, we tested for the acceptability of cantharidin-fed frogs to leeches and snakes. In the discussion, we address the issue of the potential risk incurred by humans from eating field-collected frogs.

(c) Georg Thieme Verlag Stuttgart · New York

\section{Materials and methods Frogs}

All experiments were done with leopard frogs (Rana pipiens), obtained from the Carolina Biological Supply Co. (Catalog no. L1500; frogs fed meloid beetles, Tables 2, 3) or the West Jersey Biological Supply Co. (frogs fed crystalline cantharidin; Table 1, Figs 1, 2, and snake tests). The frogs were maintained individually in large glass or plastic containers in which they were also offered their experimental insect prey. They were sexed upon dissection.

\section{Cantharidin analyses and sample preparation}

The technique used for cantharidin assay has been described (Carrel et al. 1985). In brief, it involves acid hydrolysis and repeated extraction of minced samples, followed by capillary gas chromatography using benzophenone as internal standard for cantharidin quantitation.

Table 1 Number of days that frogs in the varying-dose experiment were fed and the total quantity of cantharidin they ingested

\begin{tabular}{l|c|l}
\hline Frog & Days fed & Cantharidin ingested (mg) \\
\hline 10 & 3 & 10 \\
29 & 3 & 18 \\
$3 \circ$ & 6 & 34 \\
40 & 12 & 64 \\
50 & 12 & 71 \\
\hline
\end{tabular}

* Paper no. 95 of the series Defense Mechanisms of Arthropod'; no. 94 is LaMunyon \& Eisner, Psyche (in press)

* Present address: Department of Ecology, Ethology, and Evolution, University of Illinois, Urbana, Illinois 61801, USA 
Slime samples were collected by wiping the living frogs' surface repeatedly with a preweighed cotton swab. Weight gain of the swab, determined immediately after wiping, provided the measure of slime collected. Feces were taken directly from the cage floor. For collection of body parts, frogs were killed by freezing and dissected. Except where otherwise indicated, blood was obtained from major vessels during dissection by uptake in capillary tubes. Minimal amounts of Ringer's solution were added during dissection to prevent desiccation. The weighed slime, blood, body part, and fecal samples (wet weights for all) were stored frozen $\left(-20^{\circ} \mathrm{C}\right.$, either with or without addition of small amounts of dichloromethane) prior to analysis.

\section{Feedings of meloid beetles}

Four frogs were fed meloid beetles, two for 3 days, and two for 12 days. They were each given a new set of ten unsexed beetles nightly. The beetles, Epicauta vittata, had been field-collected on tomato plants at various sites in Boone County, Missouri. One additional frog served as control. It was given ten live late-instar mealworms (larvae of Tenebrio molitor) nightly for 13 days.

Each morning uneaten prey left by each frog were removed and counted, the number of items eaten was calculated, and feces if present were collected and weighed. Slime was collected from all five frogs at the start of the experiment (day 0 ) and on days 1 and 3; it was also collected from two of the Epicauta-fed frogs on days 9 and 12, and from the control frog on day 13 .

The frogs were killed at the end of the feeding periods and their parts dissected for analysis.

Ten $E$. vittata [unsexed; $14.7 \pm 2.6(\mathrm{SEM}) \mathrm{mg}$ ] were individually analyzed for cantharidin content. Mean value was found to be $0.75 \pm 0.14$ (SEM) $\mathrm{mg}$ cantharidin/beetle (range 0.31-1.45).

\section{Feedings of cantharidin}

Cantharidin was fed to frogs as a crystalline coating on mealworms. The chemical was added topically to individual mealworms in dichloromethane solution $(50 \mu \mathrm{l})$, drop by drop, allowing for solvent evaporation between drops, until $1 \mathrm{mg}$ cantharidin had been applied. During experimental periods frogs were offered 6 such mealworms per day.

\section{a) Cantharidin uptake as a function of dosage ingested}

To determine the amount and distribution of cantharidin in frogs fed different quantities of the chemical, 5 frogs were offered cantharidin-coated mealworms for 3 days ( 2 frogs), 6 days ( 1 frog), and 12 days ( 2 frogs). Total amount consumed per frog varied from 10 to $71 \mathrm{mg}$, since the frogs did not always eat the full daily complement of 6 mealworms (Table 1). Slime collections and organ dissections were effected 20-24 hours after the last feeding (blood was obtained from frog 1 only). Four of the frogs were male. Due to procedural faults, one set of testes and one spleen had to be excluded from analysis.

\section{b) Cantharidin retention over time}

To determine the lengths of time over which ingested cantharidin is retained by the frogs, 6 frogs were fed cantharidin-coated mealworms for 3 days, and then killed for sample collection at $1,2,4,8,16$, and 32 days after the last feeding. Slime samples were taken immediately prior to killing. Blood collections were taken from 4 of the 6 frogs only. All mealworms offered were eaten, so all frogs had consumed $18 \mathrm{mg}$ cantharidin. The frog killed on day 1 was also tallied as part of the preceeding uptake/dosage experiment (frog 2 female).

\section{Predation tests with leeches}

To determine whether acquired cantharidin conveys a measure of protection upon frogs, three cantharidin-fed (experimental) and three cantharidin-unfed (control) frogs were subjected to ectoparasitic feeding by leeches.

The experimental frogs were given a single daily complement of cantharidin-coated mealworms. Two frogs ate 5 of the 6 mealworms offered $(5 \mathrm{mg}$ cantharidin ingested), the other ate all 6 mealworms (6 mg ingested).

Twenty-four hours after feeding the frogs were restrained (to prevent them from eating the leeches) with a Trojan-Enz ${ }^{\oplus}$ condom (non-lubricated), fashioned as a girdle by removal of the receptacle tip. The device was fitted over the torso of the frog, immobilizing the front legs, but allowing head and hindlegs to project free. Experimental and control frogs were then individually offered to a single leech (Hirudo medicinalis), by the following standardized procedure.

After being taken from its tank and blotted off with absorbent paper to remove excess water, the leech was weighed and placed directly upon a hindleg of the frog, to which it promptly fastened itself. Criterion of attachment was an abrupt shortening and increase in girth of the leech's front end. After being allowed to feed for $5 \mathrm{~min}$, the leech was removed by grasping it behind the front sucker with forceps, blotted off again, and weighed. The procedure was then repeated for three additional 5 min feeding periods, and then for a further four $10 \mathrm{~min}$ feeding periods, for a total $60 \mathrm{~min}$ feeding time per leech. The leeches appeared to be satiated after $60 \mathrm{~min}$, since five of the six tested showed no appreciable weight gain in the last two or three feeding periods, and four actually detached spontaneously during the last period. The one leech that gained weight during the last period was tested for three 10-min feedings beyond the hour, but it failed to gain further weight. All frogs and leeches were tested only once.

To test for the effect of handling upon leech weight, a single additional leech was put through the full experimental protocol, except that it was removed instantly upon each attachment and weighed, before it could have initiated feeding. The leech showed a consistent but slight bodyweight loss per weighing $(\overline{\mathrm{x}}=1.9 \%$; range $0.7-3.4 \%)$.

Slime and blood samples for analysis were collected from the frogs immediately after testing. Blood was drawn from the ocular sinus with a capillary tube. 


\section{Predation tests with snakes}

Cantharidin-fed frogs were tested with a second type of predator, the broad-banded water snake (Nerodia sipedon). Sixteen frogs were offered to 4 individual Nerodia. The day before presentation to the snakes, all frogs were given a single day's regimen of 6 cantharidin-coated mealworms. Thirteen of the frogs ate the 6 mealworms, thereby acquiring $6 \mathrm{mg}$ cantharidin; the other 3 ate 3 or 4 mealworms each. The snake feedings were done over a period of 3 days. Prior to this period, over the course of several days, each snake received 9 control frogs (cantharidin-unfed). Several control frogs were also offered to the snakes during the 3-day experimental period, interspersed with the presentations of experimental frogs.

Slime was collected from the experimental frogs immediately before the presentations.

\section{Results}

\section{Feedings of meloid beetles}

As is clear from Table 2, all four frogs that ingested Epicauta produced cantharidin-laden slime and feces. The cantharidin content of the slime was in the order of less than a part per thousand. With the exception of a single sample (frog C, day 4), the cantharidin content of the feces was at roughly the same level. Although over the short term the cantharidin content of the slime showed an increase with increasing meloid intake (frogs $\mathrm{A}$ and $\mathrm{B}$ ), levels remained stable beyond the initial rise, even in the one frog (C) that ate meloids in fairly regular numbers over the full 12-day period.

As expected, no cantharidin was detected in either slime or feces of the control frog. Interestingly, this frog, unlike the Epicauta-fed frogs, consumed virtually all its prey offerings during the course of the experiment. This could indicate that Epicauta are less "appealing" than mealworms to $R$. pipiens. Indeed, when frogs $\mathrm{C}$ and $\mathrm{D}$ received a supplement of 5 mealworms each on days 7 and 12 , they consumed these offerings while leaving most of the Epicauta simultaneously available uneaten.
Table 3 Levels of cantharidin ( $\mu \mathrm{g} / \mathrm{g}$ tissue) in various body parts of frogs fed meloid beetles (Epicauta vittata). $N A=$ not analyzed due to insufficient quantity of fat

\begin{tabular}{l|r|r|r|r}
\hline Organ & \multicolumn{1}{|c|}{$\begin{array}{l}\text { Frog } \\
\text { Aq }\end{array}$} & BQ & Co & Dor \\
\hline Skin & 113 & 87 & 98 & 0 \\
Thigh muscle & 0 & 15 & 0 & 0 \\
Heart & 0 & 252 & 0 & 0 \\
Liver & 39 & 32 & 24 & 0 \\
Kidneys & 0 & 795 & 126 & 0 \\
Fat bodies & 0 & NA & NA & 0 \\
Testes and male duct & - & - & 145 & 0 \\
Ovaries and oviduct & 0 & 192 & - & - \\
\hline
\end{tabular}

The analyses of body parts of the experimental frogs (Table 3) revealed presence of cantharidin in at least some organs of frogs $\mathrm{A}, \mathrm{B}$, and $\mathrm{C}$. All these had eaten meloids to within 1 or 2 days prior to their sacrifice. The fourth frog (D), whose organs were cantharidin-free, had not consumed meloids for four days prior to its death. This frog did, however, have cantharidin in its slime (Table 2).

\section{Cantharidin uptake as a function of dosage ingested}

As is evident from the left-hand plots in Figure 1 , cantharidin contents of organs tended to be higher with increased cantharidin consumption levels only for slime, gut, and skin. Other organs displayed no clear trends. These quantitative indications need to be taken with some caution, given that the individual data points represent single samples, and that the four frogs acquired their cantharidin over different time spans. Nonetheless it is clear that following ingestion cantharidin is systemically absorbed and widely distributed through the body of the frog. Highest cantharidin levels were detected in slime and the gut. No detectable quantities were found in the liver.

Table 2 Cantharidin in slime and feces of frogs fed meloid Seetles (Epicauta vittata) or, as a control, living mealworms. Detaiís in text

\begin{tabular}{|c|c|c|c|c|c|c|c|c|c|c|c|c|c|c|c|}
\hline \multirow[t]{3}{*}{ Day } & \multicolumn{6}{|c|}{$\begin{array}{l}\text { Experimental frogs } \\
\qquad \mathrm{AO}\end{array}$} & \multicolumn{3}{|c|}{$\mathrm{Co}^{\prime}$} & \multicolumn{3}{|c|}{ Do } & \multicolumn{3}{|c|}{$\begin{array}{r}\text { Control frog } \\
\qquad E\end{array}$} \\
\hline & \multirow{2}{*}{$\begin{array}{l}\text { No. } \\
\text { Epicauta } \\
\text { eaten }\end{array}$} & \multicolumn{2}{|c|}{$\begin{array}{c}\text { Cantharidin } \\
(\mu g / g)\end{array}$} & \multirow{2}{*}{$\begin{array}{l}\text { No. } \\
\text { Epicauta } \\
\text { eaten }\end{array}$} & \multicolumn{2}{|c|}{$\begin{array}{c}\text { Cantharidin } \\
(\mu \mathrm{g} / \mathrm{g})\end{array}$} & \multirow{2}{*}{$\begin{array}{l}\text { No. } \\
\text { Epicauta } \\
\text { eaten }\end{array}$} & \multicolumn{2}{|c|}{ 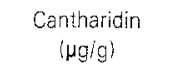 } & \multirow{2}{*}{$\begin{array}{c}\text { No. } \\
\text { Epicauta } \\
\text { eaten }\end{array}$} & \multicolumn{2}{|c|}{ 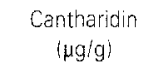 } & \multirow{2}{*}{$\begin{array}{c}\text { No. } \\
\text { mealworms } \\
\text { eaten }\end{array}$} & \multicolumn{2}{|c|}{$\begin{array}{c}\text { Cantharidin } \\
(\mu g / g)\end{array}$} \\
\hline & & slime & feces & & slime & feces & & slime & feces & & slime & feces & & slime & feces \\
\hline 0 & - & 0 & - & - & 0 & - & - & 0 & - & - & 0 & - & - & 0 & - \\
\hline 1 & 2 & 38 & 0 & 3 & 43 & - & 6 & 0 & - & 4 & 94 & - & 10 & 0 & - \\
\hline 2 & 2 & - & 10 & 1 & - & 70 & 1 & - & - & 1 & - & 29 & 10 & - & - \\
\hline 3 & 0 & 228 & - & 3 & 136 & - & 0 & 106 & - & 0 & 66 & - & 10 & 0 & - \\
\hline 4 & & & & & & & 0 & - & 6400 & 0 & - & - & 9 & - & - \\
\hline 5 & & & & & & & 3 & - & - & 0 & - & - & 10 & - & - \\
\hline 6 & & & & & & & 0 & - & - & 0 & - & - & 10 & - & - \\
\hline 7 & & & & & & & 2 & - & - & 0 & - & - & 10 & - & 0 \\
\hline 8 & & & & & & & 0 & - & - & 3 & - & - & 70 & - & - \\
\hline 9 & & & & & & & 0 & 17 & 48 & 0 & 84 & 28 & 10 & - & - \\
\hline 10 & & & & & & & 1 & - & - & 0 & - & - & 10 & - & - \\
\hline 11 & & & & & & & 1 & - & - & 0 & - & - & 10 & - & - \\
\hline 12 & & & & & & & 4 & 96 & - & 0 & 133 & - & 10 & - & - \\
\hline 13 & & & & & & & & & & & & & 10 & 0 & - \\
\hline
\end{tabular}



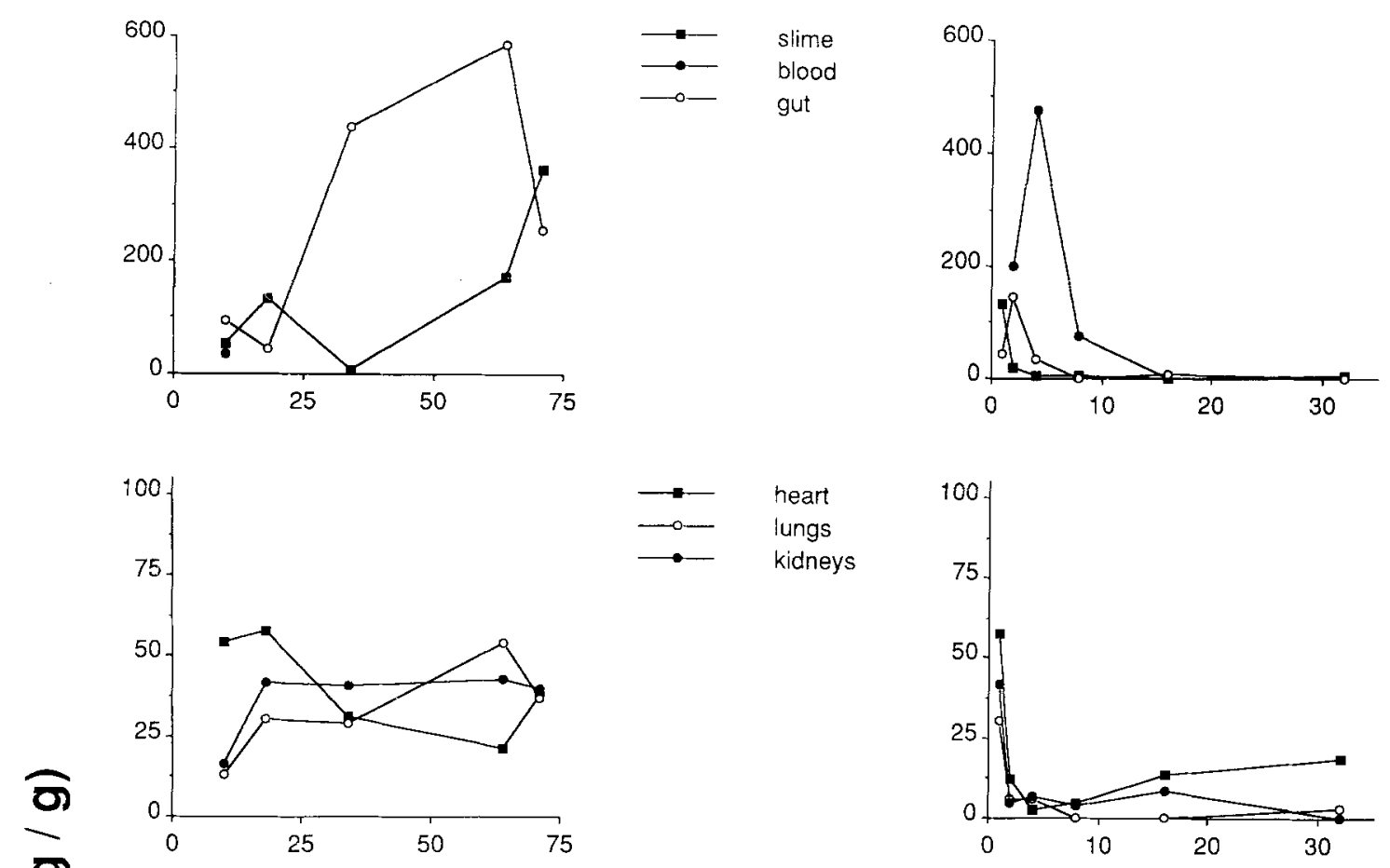

$\underline{\Xi}$
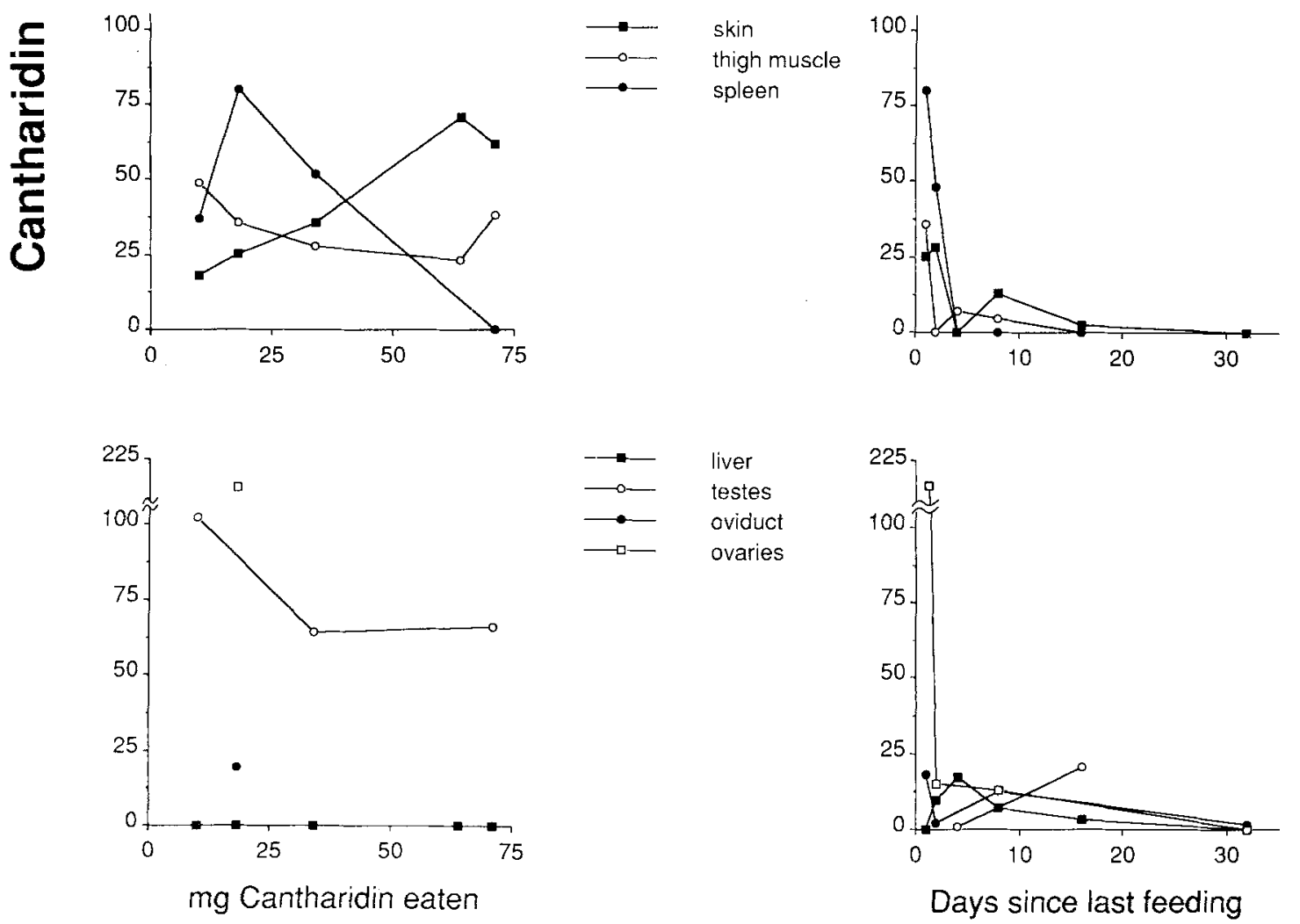

Fig. 1 Cantharidin concentration in various body parts of frogs fed cantharidin, plotted as a function of dose ingested (left-hand graphs) and time since last ingestion (right-hand graphs). Note the different $Y$-axis scale in the top two plots. In the dose data there are only single data points for blood, ovary and oviduct 


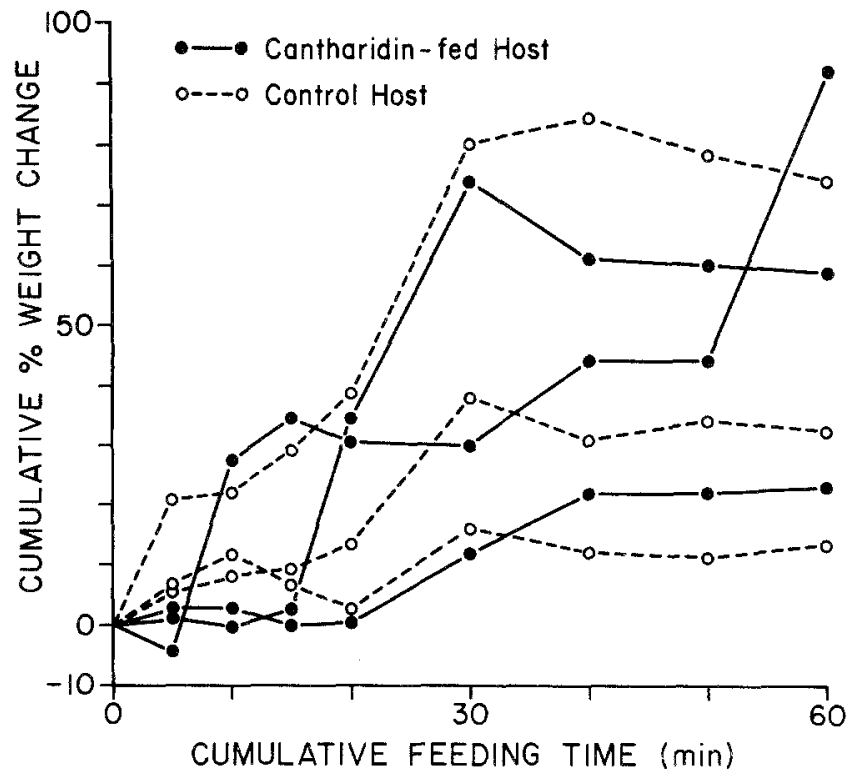

Fig. 2 Cumulative percent weight gain of leeches, plotted as a function of total time spent feeding on control frogs (dashed lines) and cantharidin-fed frogs (solid lines)

\section{Cantharidin retention over time}

The right-hand plots in Figure 1 reveal that for most organs, cantharidin levels declined rapidly within the first day(s) after cessation of intake of the compound.

\section{Predation tests with leeches}

As evidenced by Figure 2, there was essentially no difference in the weight gain of leeches fed on cantharidin-fed frogs and those fed on control frogs. The cantharidin levels in slime and blood of the 3 cantharidin-fed frogs were respectively $30,162,217$ and $212,157,1430 \mu \mathrm{g} / \mathrm{g}$.

\section{Predation tests with snakes}

The 4 snakes showed essentially the same behavior toward the cantharidin-fed frogs as toward controls. Fifteen of the 16 cantharidin-fed frogs were eaten. They were each grasped and methodically swallowed, as is typically the case, without undue delay. One snake was noted to go through a cycle of swallowing and regurgitating a frog, before reswallowing and retaining it. The 1 cantharidin-fed frog that was not eaten was ignored by each of 3 snakes to which it was presented. Such failure to respond was also occasionally noted with presentations of control frogs.

The snakes suffered no noticeable ill-effects from the feedings. They were in excellent condition when released at their capture sites 10 days after experimentation.

Nine of the 16 experimental frogs proved to contain cantharidin in their slime $[220 \pm 109(\bar{x} \pm$ SEM) $\mu \mathrm{g} / \mathrm{g}$; range 71-403]. Cantharidin was not detected in the slime of the other 7 frogs.

\section{Discussion}

A number of animals, tolerant of toxic chemicals, incorporate such substances systemically when they acquire them in the diet. Particularly well-known are cases involving insects that sequester toxins from plants (Brattsten 1986). Instances involving vertebrates appear to be rare, but this may reflect merely that they remain to be discovered. Substantiated cases are those of marine fish that are rendered poisonous through ingestion of algae (Comm. Food Protect. 1973; Liener 1974). The data we present here prove that frogs can incorporate dietary cantharidin, a compound available to them through Meloidae, beetles they are bound to encounter in nature and known to eat (Vézien 1861; Korschgen \& Moyle 1955).

The systemic retention of cantharidin by frogs is time-limited. Within a few days after cessation of ingestion of either Epicauta or crystalline cantharidin, $R$. pipiens no longer harbor substantial quantities of the compound. We cannot be certain whether cantharidin is excreted, metabolically degraded, or both, over time, but the fact that after ingestion it is on the short term always present in the slime suggests that it is at least in part voided by integumental excretion. The cantharidin we detected in the feces of the frogs could have represented enterically unabsorbed chemical, as well as possibly previously-absorbed chemical excreted by the kidneys. Based on the relatively few frogs that we dissected for analyses, little can be said about the postabsorptive systemic distribution routes of cantharidin in Rana except that the substance appears to find its way to virtually all body parts.

The quantities of crystalline cantharidin fed to our frogs were commensurate with amounts one could expect Rana to acquire in nature through meloid beetle ingestion. In fact, the amount of cantharidin we applied topically to individual mealworms $(1 \mathrm{mg})$ was in line with the mean total body cantharidin content $(0.75 \mathrm{mg})$ of the Epicauta we tested. Meloid beetles may contain upward of $20 \mathrm{mg}$ cantharidin per individual (McCormick \& Carrel 1987).

Although systemic cantharidin declines rapidly after acquisition in Rana, persistent internal levels could be maintained by frogs through ongoing ingestion of the compound (witness the continuous production of cantharidin-laden slime by frogs $C$ and D, Table 2). Meloids frequently live in dense aggregations, persistent both in time and place. During periods when such aggregations are within foraging access of frogs, the latter could remain cantharidin-laden for days or even weeks at a time.

The finding that neither leeches nor snakes were deterred by the presence of cantharidin in their prey was somewhat unexpected. Given that meloid beetles use the compound for defense, one might have envisioned the frogs themselves to benefit from acquisition of the compound. Defensive employ by animals, particularly insects, of toxins that they acquire from the diet has been repeatedly demonstrated (Harborne 1988). Of course, neither oral sensitivity nor behavioral aversion to cantharidin had previously been shown for leeches or snakes. It is certainly possible that other predlators (avian? mammalian?) might find cantharidin-laden frogs unpalatable. Mere contact with the skin of a laden frog could lead to rejec- 
tion by an appropriately sensitive predator, since the compound is deployed externally by the frog as part of its slime. Of particular interest would be determining whether acquired cantharidin in female frogs is transmitted to the eggs, and whether these might be protected or affected as a result. Our finding that ingested cantharidin finds its way into the ovaries of Rana is tantalizing in this respect.

Of special significance is the potential dietary hazard posed by cantharidin-containing frogs to humans. The cases reported by Vézien (1861) and Meynier (1893) are already revealing in this regard. Our data suggest that frogs could be potently toxic to humans even after ingesting only moderate numbers of meloids. Frogs which in our uptake/dosage experiment had consumed $10-71 \mathrm{mg}$ cantharidin (equivalent to $13-95 E$. vittata) over spans of 3 to 12 days had cantharidin levels of 25 to $50 \mathrm{mg} / \mathrm{g}$ in the thigh muscle. If the lethal human dose for cantharidin is taken at $10 \mathrm{mg}$ /person (a value that is "not well established"; Till \& Majmudar 1981), a meal of 200 to 400 grams of frog legs could potentially be fatal. Since cantharidin is seriously injurious even at sublethal dosages (Kaiser \& Michl 1958; Polson \& Tattersall 1959), frogs with even lesser quantities of cantharidin could be harmful. We do not know how widespread meloid consumption is in frogs eaten worldwide by humans. However, it seems clear that field-collected frogs can be dietarily endangering, if they come from a region where meloids abound, and if they are eaten shortly after capture, while still potentially laden with cantharidin.

\section{Acknowledgments}

Supported in part by grant AI 02908 from NIH. We thank P. Fraissinet, D. Sanders, J. Doom, K. Smith, and S. Miller for technical assistance.

\section{Note added in proof}

The following information, provided by Stefan Krall (GTZ, Eschborn, FRG), was relayed to me by courtesy of Michael Boppré:

In North Bénin, on the Niger, there are several species of Meloidae that are agricultural pests. The beetles aggregate in large numbers at light and may induce skin irritation and even dermal scarring in natives exposed to them. Spur-winged gees (Plectropterus gambensis (L.)) feed on the meloids and are eagerly hunted and eaten by the natives. European visitors have been known to experience strong erections following ingestion of such gees, indicating that the birds retain cantharidin and the chemical is unaffected by cooking. No information is available on whether natives are similarly affected.

T. Eisner

\section{References}

Brattsten LB (1986) Fate of ingested plant allelochemicals in herbivorous insects. Pp 211-255 in Brattsten LB \& Ahmad S (eds) Molecular Aspects of Insect-Plant Associations. New York: Plenum Press

Carrel JE, Eisner T (1974) Cantharidin: potent feeding deterrent to insects. Science 183:755-757

Carrel JE, Doom JP, McCormick JP (1985) Quantitative determination of cantharidin in biological materials using capillarygas chromatography with flame ionization detection. J Chromatog Biomed Appl 342:411415

Committee on Food Protection, National Research Council (1973) Toxicants occurring naturally in foods. Washington, D.C.: National Academy Sciences Press

Harborne JB (1988) Introduction to Ecological Biochemistry. New York: Academic Press

Kaiser E, Michl H (1958) Die Biochemie der tierischen Gifte. Wien: Franz Deuticke

Kelling ST, Halpern BP \& Eisner T (1990) Gustatory sensitivity of an anuran to cantharidin. Experientia (in press)

Korschgen LJ, Moyle DL (1955) Food habits of the bullfrog in central Missouri farm ponds. Amer Midland Naturalist 54:332-341

Liener IE (1974) Toxic Constituents of Animal Foodstuffs. New York: Academic Press

McCormick JP, Carrel JE (1987) Cantharidin biosynthesis and function in meloid beetles. Pp 307-350 in Prestwich GD \& Blomquist HF (eds) Pheromone Biochemistry. Orlando: Harcourt, Brace, Jovanovich

Meynier J (1893) Empoisonnement par la chair de grenovilles infestées par des insectes du genre Mylabris de la famille des méloides. Archiv de Medicine et de Pharmacie Militaires 22:53-56

Polson CJ, Tattersall RN (1959) Clinical Toxicology. Philadelphia: Lippincot

Till JS, Majmudar BN (1981) Cantharidin poisoning. Southern Med J $74: 444-447$

Vézien M (1861) Note sur la cystide cantharidienne par l'ingestion de grenouilies qui sont nourries de coléoptères vésicants. Recueil de Mémoires de Medicine de Chirurgie et de Pharmacie Militaires 4:457-460 